\title{
AVALIAÇÃO DO USO DE PROCESSOS DE SEPARAÇÃO POR MEMBRANAS EM EFLUENTES DE LATICÍNIOS PRÉ- TRATADOS POR COAGULAÇÃO/FLOCULAÇÃO
}

\author{
P. R. A. MENDES ${ }^{1}$, L. F. F. FARIA ${ }^{1}$ \\ ${ }^{1}$ Escola de Engenharia de Lorena/USP, Departamento de Engenharia Química \\ E-mail para paulo_ricardo_am@yahoo.com.br
}

\begin{abstract}
RESUMO - O presente trabalho objetiva avaliar o uso de membranas de microfiltração (MF) e ultrafiltração (UF) em um efluente de laticínios oriundo da produção de queijos, visando à remoção de contaminantes coloidais e de alta massa molar ainda presentes. Este efluente consiste no concentrado de soro de queijo nanofiltrado, pré-tratado por coagulação/floculação. Para isso foram usadas membranas do tipo fibra oca de MF de $0,40 \mu \mathrm{m}$ em polieterimida e UF de $50 \mathrm{kDa}$ em polietersulfona, sendo que os permeados foram comparados quanto as alterações físico-químicas juntamente com os valores de fluxo obtidos para cada membrana. Os permeados de ambas as membranas não apresentaram diferenças significativas quanto às reduções de DQO $(5,83 \pm 0,40$ e $5,21 \pm 0,30 \%)$ COT $(2,71 \pm 0,07$ e $1,25 \pm 0,10 \%)$ e turbidez $(99,4 \pm 0,1$ e $87,4 \pm 0,1 \%)$ respectivamente para UF e MF. Contudo, a permeabilidade ao efluente na UF foi de $1,79 \mathrm{~L} \mathrm{~h}^{-1} \mathrm{~m}^{-2}$ bar $^{-1}$ e na MF foi de 46,6 $\mathrm{L} \mathrm{h}^{-1} \mathrm{~m}^{-2}$ bar $^{-1}$, representando uma diferença de 96,2\%. Assim, a membrana de MF foi escolhida e submetida a testes de recuperação de fluxo com diferentes soluções de limpeza, na busca da viabilidade de uso por longos períodos.
\end{abstract}

\section{INTRODUÇÃO}

A disposição do soro de queijo, o principal efluente da indústria de laticínios, é uma das maiores dificuldades enfrentadas pelas indústrias do ramo. A geração mundial anual de soro é de cerca de 190 milhões de toneladas, sendo que somente $50 \%$ deste total são aproveitados pelas indústrias e o restante torna-se um grande inconveniente, em termos de tratamento. Estes efluentes poluem, principalmente, por causa de sua elevada quantidade de matéria orgânica, devendo ser previamente tratado antes do seu despejo (Baldasso et al., 2011). Para o tratamento do soro de queijo estão disponíveis várias técnicas podendo ser físicas, químicas e biológicas, bem como combinações destas técnicas a fim de aperfeiçoar o tratamento, considerando que cada técnica possui limitações em eficiência e custo.

Dentre os tratamentos convencionais disponíveis, destaca-se a coagulação/floculação por sua elevada eficiência na remoção de partículas coloidais e suspensas (minerais e orgânicas), que promovem turbidez e cor, que não são facilmente removidas por sedimentação (Pritchard et al., 2010). Vários estudos vêm sendo feitos com coagulantes de 
origem natural no intuito de substituir ou auxiliar os coagulantes convencionais, em tratamentos de efluentes. Estes coagulantes são biodegradáveis, poluem menos que os químicos, gerando assim lodos e efluentes de menor toxicidade, merecendo destaque a quitosana, os derivados de tanino vegetal e sementes de Moringa oleifera (Cardoso et al., 2008; Pritchard et al., 2010).

As membranas de MF e UF são muito utilizadas no setor alimentício, com aplicações que envolvem a purificação e concentração de substâncias até no tratamento de efluentes. As membranas de MF atuam na faixa de tamanho de poros de 10 a $0,1 \mu \mathrm{m}$ para a remoção de partículas em suspensão, emulsões e microrganismos. Já a UF, que apresenta tamanho de poro menor $(0,1$ a $0,001 \mu \mathrm{m})$, consegue fracionar ou concentrar macromoléculas, como carboidratos e proteínas. Ambos os processos, tem como força motriz o gradiente de pressão, sendo de 0,1 a 3,5 bar para MF e de 1,0 a 7,0 bar para UF (Mulder, 1996; Habert et al., 2006). No entanto, alguns problemas estão associados ao uso das membranas de MF e UF, sendo os principais o fouling e polarização de concentração, que proporcionam a redução do fluxo permeado (Mulder, 1996). Os efeitos relacionados à polarização de concentração não podem ser evitados, no entanto podem ser controlados por condições operacionais (baixas pressões de trabalho e fluxo turbulento sobre a superfície da membrana) (Habert et al., 2006). Com relação ao fouling, que é a incrustação indesejável de partículas dissolvidas, suspensas ou coloidais de modo reversível ou irreversível na membrana, um pré-tratamento com coagulação/floculação pode ajudar a controla-lo e melhorar a produtividade da membrana, pois este processo consegue reduzir materiais suspensos e coloidais que colaboram para o aumento da turbidez e que influenciam na DQO e DBO (Bergamasco et al., 2011).

Bergamasco et al. (2009) trataram águas superficiais fazendo uso de processos combinados utilizando quitosana como coagulante e floculante seguido de microfiltração com membrana de tamanho de poro de $0,1 \mu \mathrm{m}$. Na etapa de coagulação/floculação foi removido $9 \%$ de (carbono orgânico total) COT e $65 \%$ do ferro, mas quando foi posteriormente realizada a etapa de microfiltração, as reduções foram superiores a $47 \%$ de COT e $100 \%$ de ferro.

Para os efluentes de laticínios é amplamente aceito que as proteínas e os minerais constituintes são que mais contribuem para a formação do fouling. As membranas incrustadas, principalmente por material proteico, são particularmente as mais difíceis de serem recuperadas. A limpeza química é uma das práticas mais comuns para regeneração destas membranas, podendo ser empregados diferentes agentes de limpeza, dentre os mais comuns têm-se os básicos $(\mathrm{NaOH})$, ácidos $\left(\mathrm{HCl}, \mathrm{H}_{3} \mathrm{PO}_{4}\right.$, ácido cítrico), surfactantes, desinfetantes $\left(\mathrm{NaClO}, \mathrm{H}_{2} \mathrm{O}_{2}\right)$ e enzimáticos (amilases e proteases). A eficiência da limpeza é avaliada por meio de medição de fluxo antes e depois do procedimento de lavagem baseado na recuperação do fluxo permeado (Petrus et al., 2008).

Assim, como objetivo deste trabalho, um efluente de laticínios previamente tratado por coagulação/floculação foi submetido a processos de separação por membranas de MF e UF para remoção de contaminantes coloidais e de alta massa molar. Como complemento desta etapa, foram realizados testes de recuperação de fluxo através de procedimentos de limpeza para a melhor membrana. 


\section{MATERIAIS E MÉTODOS}

O efluente foi gentilmente cedido pela empresa Danubio (Dan Vigor Indústria e Comércio de Laticínios Ltda.), sediada na cidade de Cruzeiro/SP, Brasil, sendo o concentrado obtido a partir de uma etapa do processo denominada de nanofiltração. Neste material foram adicionados $0,10 \%$ de biocida IPEL BP-15 para evitar a contaminação e conservado em câmara fria a $4{ }^{\circ} \mathrm{C}$, para manter suas características físico-químicas durante os tratamentos.

Foram utilizados como coagulantes naturais, derivado de tanino Biosugar (Acquaquímica S/A) e sementes de Moringa oleifera (gentilmente cedidas pela Universidade Federal de Sergipe e Universidade Estadual de Maringá). Os reagentes analíticos utilizados possuem grau P.A. (Merck, Vetec, Synth, Aldrich). As amostras foram analisadas quanto à DQO, DBO, COT, sólidos, $\mathrm{pH}$, condutividade elétrica e turbidez conforme Standard methods for the examination of water and wastewater, $20^{\text {th }}$ edition. A lactose foi determinada por cromatografia líquida de alta eficiência de fase reversa.

O efluente foi previamente tratado por coagulação/floculação envolvendo agentes naturais em temperatura ambiente em condição proposta por Mendes (2014) descrita a seguir. Após o ajuste do pH do efluente $(8,3)$ e posterior filtração, o sobrenadante foi transferido para cubas de Jar Test de 2 litros de volume, sendo adicionada uma mistura de coagulantes em concentrações de $265 \mathrm{mg} \mathrm{L}^{-1}$ de moringa e $430 \mathrm{mg} \mathrm{L}^{-1}$ de tanino, seguida de homogeneização a $120 \mathrm{rpm}$ por 1 minuto. Ao final desta etapa, foi empregada agitação intermitente (15 minutos de agitação a $10 \mathrm{rpm}$ e 45 minutos de repouso) por 6 horas. O sobrenadante coagulado/floculado foi submetido aos processos com membranas. As membranas utilizadas neste trabalho foram do tipo fibra oca, com comprimento útil de $260 \mathrm{~mm}$, área de permeação útil de $0,072 \mathrm{~m}^{2}$ e densidade de empacotamento de $800 \mathrm{~m}^{2} / \mathrm{m}^{3}$, ambas adquiridas da empresa PAM Membranas. A membrana de MF (polieterimida) possui tamanho de poro de $0,40 \mu \mathrm{m} \mathrm{e}$ a de UF (polietersulfona), ponto de corte de $50 \mathrm{kDa}$.

Para analisar o desempenho das membranas, inicialmente as mesmas foram compactadas a pressões de 1,2 bar e 2,2 bar para a MF e UF, respectivamente. A seguir foram realizados testes para determinação da permeabilidade hidráulica com água deionizada e microfiltrada antes da permeação com o efluente, em diferentes pressões de trabalho para ambas as membranas. As medidas de fluxo permeado foram realizadas em triplicatas. Em seguida, foi determinada a permeabilidade do efluente tratado, também para as membranas testadas.

Para a membrana selecionada foi proposto o emprego de lavagens sucessivas por diferentes soluções de limpezas e procedimentos a fim de recuperar periodicamente o fluxo permeado destas membranas. As condições de lavagem investigadas foram:

- Lavagem convencional com água microfiltrada seguida por solução de $\mathrm{Ca}(\mathrm{ClO})_{2}$ $0,5 \mathrm{~g} \mathrm{~L}^{-1}$ por $0,5 \mathrm{~h}$;

- Lavagem convencional com água microfiltrada seguida por solução de $\mathrm{Ca}(\mathrm{ClO})_{2}$ $0,5 \mathrm{~g} \mathrm{~L}^{-1}$ por $1,0 \mathrm{~h}$; 
- Lavagem convencional com água microfiltrada seguida por solução alcalina $(\mathrm{NaOH}$ $-\mathrm{pH} 10,0)$ por $18 \mathrm{~h}$;

- Retrolavagem com água microfiltrada seguida por solução de $\mathrm{NaClO} 0,5 \mathrm{~g} \mathrm{~L}^{-1}$ por $1,0 \mathrm{~h}$;

- Retrolavagem com água microfiltrada seguida por solução de $\mathrm{NaClO} 1,0 \mathrm{~g} \mathrm{~L}^{-1}$ por $1,0 \mathrm{~h}$;

- Retrolavagem com água microfiltrada seguida por solução de $\mathrm{NaClO} 1,0 \mathrm{~g} \mathrm{~L}^{-1}$ por $2,0 \mathrm{~h}$.

\section{RESULTADOS E DISCUSSÃO}

Após o pré-tratamento do efluente por coagulação/floculação, as amostras foram caracterizadas e os resultados são mostrados na Tabela 1. De acordo com os valores obtidos para DQO e COT, este efluente bruto apresenta elevados teores de matéria orgânica dissolvida, principalmente, ocasionados pela presença de lactose. A razão DBO/DQO de 0,13 mostra que este efluente causaria sobrecarga em sistemas de tratamento biológico.

Tabela 1 - Caracterização do efluente coagulado/floculado.

\begin{tabular}{cc}
\hline Parâmetros & $\begin{array}{c}\text { Efluente } \\
\text { coagulado/floculado }\end{array}$ \\
\hline $\mathrm{pH}$ & $7,56 \pm 0,01$ \\
Condutividade elétrica $\left(\mathrm{mS} \mathrm{cm}^{-1}\right)$ & $8,68 \pm 0,04$ \\
DQO $\left(\mathrm{mg} \mathrm{L}^{-1}\right)$ & $224.800 \pm 432$ \\
COT $\left(\mathrm{mg} \mathrm{L}^{-1}\right)$ & $78.920 \pm 353$ \\
DBO $\left(\mathrm{mg} \mathrm{L}^{-1}\right)$ & $29.400 \pm 641$ \\
Turbidez $\left(\mathrm{NTU}^{-1}\right)$ & $28,4 \pm 0,1$ \\
Sólidos totais $\left(\mathrm{g} \mathrm{L}^{-1}\right)$ & $211,8 \pm 4,0$ \\
Sólidos dissolvidos $\left(\mathrm{g} \mathrm{L}^{-1}\right)$ & $203,6 \pm 4,1$ \\
Lactose $\left(\mathrm{g} \mathrm{L}^{-1}\right)$ & $203,0 \pm 0,2$ \\
\hline
\end{tabular}

A seguir, foram realizados os testes de permeabilidade hidráulica e do efluente prétratado utilizando a membana de $\mathrm{MF}$ e os resultados obtidos são apresentados na Figura 1. Com a realização destes ensaios pode-se constatar que houve uma diminuição de 70,2\% entre as permeabilidades obtidas para a mesma membrana. Essa redução ocorreu possivelmente pela quantidade de materiais particulados maiores que o poro da membrana presentes no efluente que ficaram retidos na superfície das fibras, dificultado a permeação, causando resistência ao fluxo.

Posteriormente, foi realizado o mesmo ensaio para as membranas de UF, usando água microfiltrada para determinação da permeabilidade hidráulica, obtendo um valor de 48,92 $\mathrm{L} \mathrm{h}^{-1} \mathrm{~m}^{-2}$ bar $^{-1}$. A permeabilidade do efluente obtida foi de 1,79 $\mathrm{L} \mathrm{h}^{-1} \mathrm{~m}^{-2}$ bar $^{-1}$ (Figura 2), indicando uma perda de permeabilidade mais drástica, chegando a um valor de 96,3\%. Possivelmente esta intensa redução ocorreu devido principalmente às características hidrofóbicas da membrana e provável fouling de macromoléculas sob a superfície da membrana e paredes dos poros, pois estas substâncias adsorvem facilmente causando maior resistência ao fluxo. 


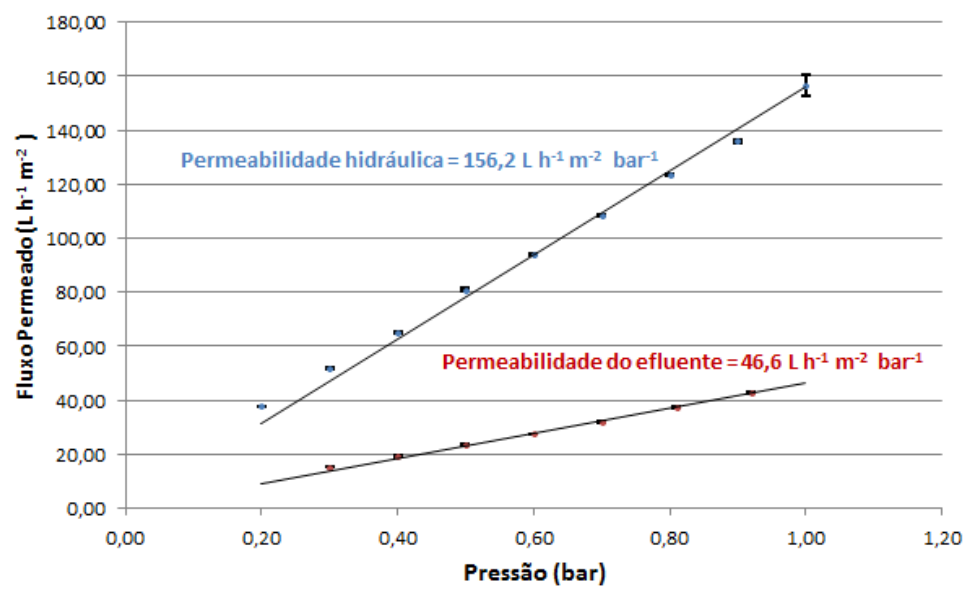

Figura 1 - Permeabilidades hidráulica e do efluente para a membrana de MF.

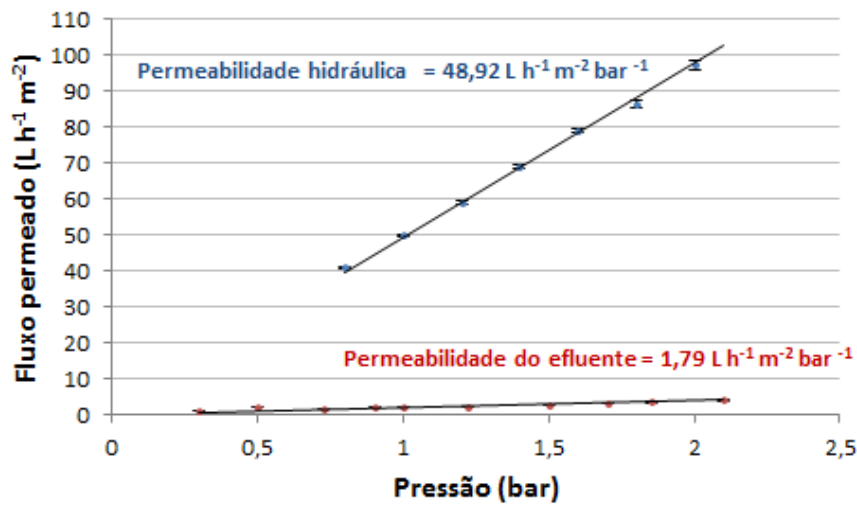

Figura 2 - Permeabilidades hidráulica e do efluente para a membrana de UF.

A seguir foram realizadas novas permeações do efluente tratado por coagulação/floculação para ambas as membranas e os permeados gerados foram caracterizados. Os resultados obtidos são apresentados na Tabela 2.

Tabela 2 - Caracterização das correntes de permeado obtidas nos ensaios de MF e UF.

\begin{tabular}{cccc}
\hline Parâmetros & $\begin{array}{c}\text { Efluente } \\
\text { coagulado/floculado }\end{array}$ & $\begin{array}{c}\text { Membrana } \\
\text { MF }\end{array}$ & $\begin{array}{c}\text { Membrana } \\
\text { UF }\end{array}$ \\
\hline DQO $\left(\mathrm{g} \mathrm{L}^{-1}\right)$ & $224,8 \pm 0,4$ & $213,1 \pm 0,5$ & $211,7 \pm 1,4$ \\
COT $\left(\mathrm{g} \mathrm{L}^{-1}\right)$ & $78,92 \pm 0,35$ & $77,93 \pm 0,42$ & $76,78 \pm 0,40$ \\
DBO $\left(\mathrm{g} \mathrm{L}^{-1}\right)$ & $29,40 \pm 0,64$ & $23,63 \pm 0,71$ & $20,50 \pm 0,69$ \\
Turbidez $(\mathrm{NTU})$ & $28,4 \pm 0,1$ & $3,59 \pm 0,04$ & $0,18 \pm 0,06$ \\
Sólidos totais $\left(\mathrm{g} \mathrm{L}^{-1}\right)$ & $211,8 \pm 4,0$ & $202,2 \pm 3,2$ & $199,1 \pm 5,1$ \\
Sólidos suspensos $\left(\mathrm{g} \mathrm{L}^{-1}\right)$ & $8,204 \pm 0,200$ & $7,050 \pm 0,347$ & $4,900 \pm 0,425$ \\
Sólidos dissolvidos $\left(\mathrm{g} \mathrm{L}^{-1}\right)$ & $203,6 \pm 4,1$ & $195,2 \pm 3,8$ & $194,2 \pm 7,2$ \\
Lactose $\left(\mathrm{g} \mathrm{L}^{-1}\right)$ & $203,0 \pm 0,2$ & $198,0 \pm 0,1$ & $196,5 \pm 0,1$ \\
\hline
\end{tabular}

As reduções dos contaminantes não foram significativas apesar de semelhantes para ambos permeados de MF e UF. A exceção foi para o parâmetro turbidez onde a MF e a UF forneceram permeados com reduções maiores que $87 \%$. Isso ocorreu provavelmente devido 
ao fato de que estes tipos de membranas não conseguirem atuar na redução da lactose, principal responsável pelos elevados valores de COT, DQO e DBO. Para UF as reduções promovidas foram de $5,83 \pm 0,40 \%, 2,71 \pm 0,07 \%, 30,3 \pm 0,9 \%$ e $99,4 \pm 0,1 \%$ em DQO, COT,

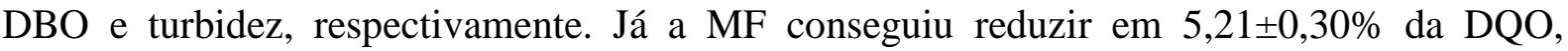
$1,25 \pm 0,10 \%$ do COT, $19,6 \pm 0,7 \%$ da DBO e $87,4 \pm 0,1 \%$ da turbidez. Vale destacar as elevadas reduções de turbidez para ambas as membranas que ocorreram, provavelmente, devido à expressiva remoção de contaminantes em suspensão e macromoléculas presentes.

Em síntese, é possível afirmar que a membrana de UF foi ligeiramente mais eficiente, porém devido a grande diferença entre as permeabilidades do efluente a favor das membranas de MF, optou-se em avaliar a capacidade operacional desta membrana ao longo do tempo a fim de justificar a sua escolha como a ideal. Para isso foi proposto o emprego de lavagens sucessivas por diferentes soluções de limpeza e procedimentos a fim de recuperar periodicamente o fluxo permeado das membranas de MF, conforme descrito anteriormente. $\mathrm{O}$ limite indicativo para o início de cada lavagem consistia na redução de $50 \%$ do fluxo permeado inicial. Os resultados obtidos são mostrados na Figura 3.

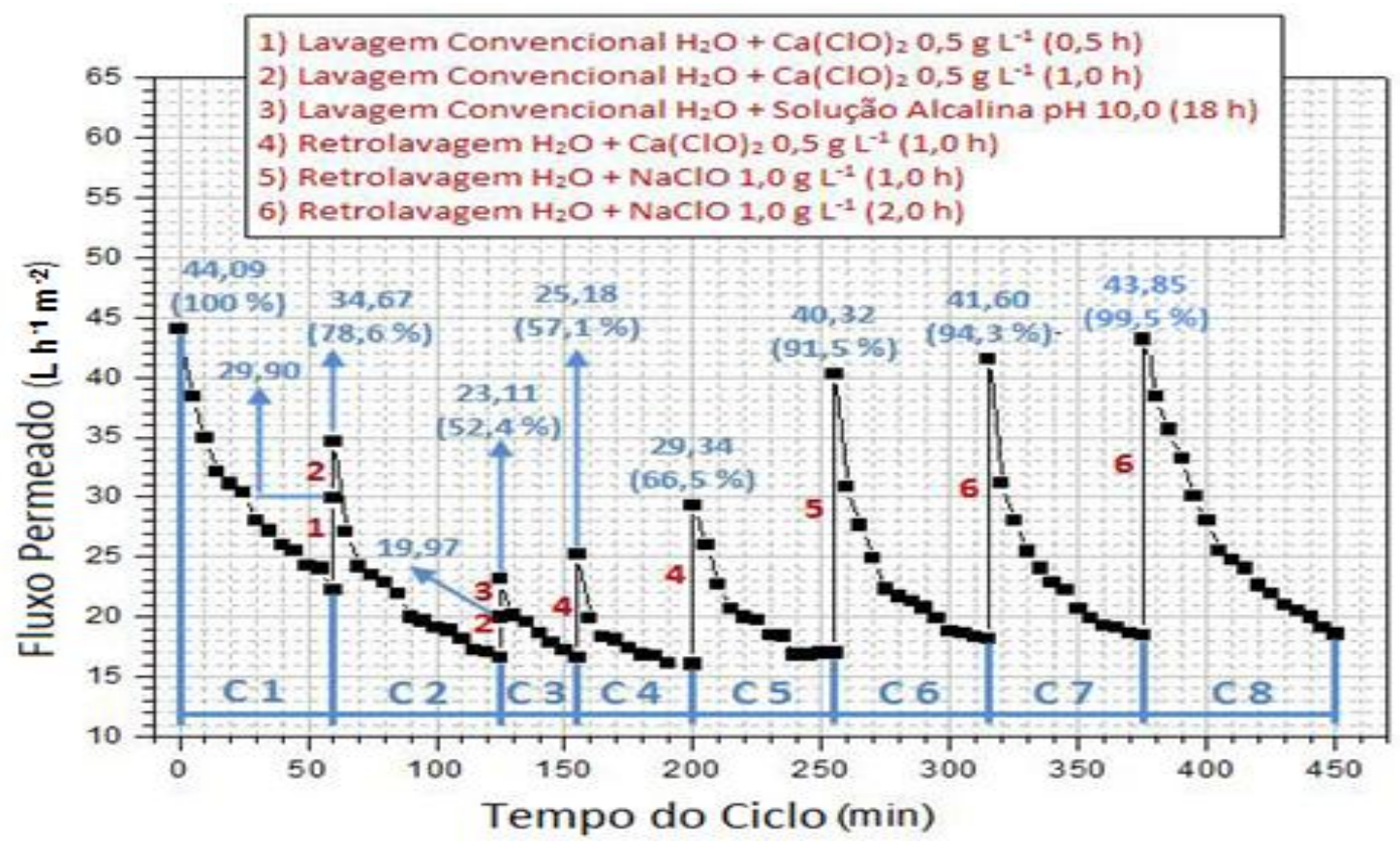

Figura 3 - Valores de Recuperação de fluxo permeado para a membrana de $\mathrm{MF}(\Delta \mathrm{P}=0,5$ bar) para cada ciclo de lavagem.

Dentre os ciclos de limpeza utilizados, as taxas de recuperação variaram entre 52,4\% e 99,5\%. A retrolavagem com água microfiltrada foi mais eficiente que a lavagem convencional, pois possibilitou que materiais particulados que estavam adsorvidos na superfície da membrana fossem mais facilmente removidos, quando comparado com o $\mathrm{Ca}(\mathrm{ClO})_{2}$ no mesmo tempo de contato. Quando foram utilizados tempos maiores de contato com as soluções de $\mathrm{Ca}(\mathrm{ClO})_{2}$ e $\mathrm{NaClO}$, as maiores taxas de recuperação de fluxo foram 
obtidas com uso associado da retrolavagem, possibilitando a recuperação quase que total do fluxo inicial. A partir destes resultados ficou comprovado a necessidade de um tempo de contato adequado entre a solução de limpeza e as membranas a fim de garantir recuperações significativas do fluxo (próximas a 99\%) prolongando, assim, a vida útil das membranas e, por consequência, possibilitando a obtenção de maiores volumes de permeado tratado por unidade de membrana.

\section{CONCLUSÃO}

Pode-se observar que ambas as membranas apresentaram reduções dos parâmetros COT, DQO e DBO muito similares, no entanto, pouco significativas. Contudo, o valor da turbidez foi bastante expressivo alcançando um resultado próximo a $90 \%$ na $\mathrm{MF}$; provavelmente devido à remoção de materiais em suspensão. Vale ressaltar que esta característica é um indicativo indireto da quantidade de materiais sedimentáveis que, por sua vez, é um parâmetro de controle de lançamento de efluentes estabelecido na legislação federal.

A retenção destes materiais na superfície da membrana promoveu a formação de incrustação que provocou baixas permeabilidades para as membranas testadas em particular para as membranas de UF.

Para a membrana de MF, escolhida e submetida aos testes de limpeza e recuperação de fluxo, foi possível observar que o uso de retrolavagem com solução a $1,0 \mathrm{~g} \mathrm{~L}^{-1}$ de hipoclorito e tempo de contato por 2 horas foi suficiente para viabilizar o uso da mesma membrana por longos períodos.

\section{REFERÊNCIAS}

BALDASSO, C.; BARROS, T.C.; TESSARO, I.C. Concentration and purification of whey proteins by ultrafiltration. Desalination, v. 278, p. 381-386, 2011.

BERGAMASCO, R.; BOUCHARD, C.; SILVA, F. V. da.; REIS, M. H. M.; FAGUNDESKLEN, M. R. An application of chitosan as a coagulant/flocculant in a microfiltration process of natural water. Desalination, v. 245, p. 205-213, 2009.

BERGAMASCO, R.; KONRADT-MORAES, L.C.; VIEIRA, M.F.; FAGUNDES-KLEN, M.R.; VIEIRA, A.M.S. Performance of coagulation-ultrafiltration hybrid process for water supply treatment. Chemical Engineering Journal, v. 166, 483-489, 2011.

CARDOSO, K. C; BERGAMASCO, R; COSSICH, E.S; MORAES, C.K. Otimização dos tempos de mistura e decantação no processo de coagulação/floculação da água bruta por meio da Moringa oleifera Lam. Acta Scientiarum - Technology, v. 30, n.2, p. 193-198, 2008 .

HABERT, A.C.; BORGES, C.P.; NOBREGA, R. Processos de separação por Membranas. 
Rio de Janeiro: Escola Piloto de Engenharia Química, 2006.

MENDES, P.R.A. Integração de processos físico-químicos e oxidativos avançados no tratamento de efluentes da indústria de laticínios. 2014. 163p. Dissertação (Mestrado em Ciências) - Escola de Engenharia de Lorena, Universidade de São Paulo, Lorena, 2014.

MULDER, M. Basic principles of membrane technology. Netherlands: Kluwer Academic Publisher, 1996.

PETRUS, H.B.; CHEN, H.L.; NORAZMAN, N. Enzymatic cleaning of ultrafiltration membranes fouled by protein mixture solutions. Journal of Membrane Science, v. 325, p. 783-792, 2008.

PRITCHARD, M.; CRAVEN, T.; MKANDAWIRE, T.; EDMONDSON, A. S.; O’NEILL, J. G. A comparison between Moringa oleifera and chemicals coagulants in the purification of drinking water: Wastewater Engineering: Treatment, Disposal, Reuse An alternative sustainable solution for development countries. Physics and Chemistry of the Earth, v. 35, p. 791-797, 2010. 